\title{
Inhumane treatment of nonhuman primate researchers
}

\author{
Animal rights extremists are threatening nonhuman primate research by harassing scientists. We cannot tolerate \\ these tactics, and we must rally individual, institutional and governmental support to protect scientists.
}

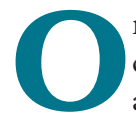

n 28 April 2015 a disturbing message shocked the neuroscience community. Nikos Logothetis, in a letter to colleagues, announced that he has decided to cease his work with nonhuman primates and will instead exclusively study neural networks in rodents. As nonhuman primate researchers go, Logothetis is legendary. Why, then, is he abandoning such a prolific and fruitful line of research? Since last fall, Logothetis and his laboratory at the Max Planck Institute for Biological Cybernetics have been targets of, as described by Logothetis, a "never-ending stream of abuse" by animal rights activists. Sadly, these intimidation tactics were successful-an undeserved win for extremist activists and a critical loss for neuroscience. Certainly, activists have the right to express their views or pursue change through appropriate political means. However, abusive campaigns should not be tolerated. We must take action to ensure scientists' safety and protect their research.

Radical activist efforts are not only malicious, they are mistaken. Part of the extreme animal rights movement's success lies in the lack of a true understanding of the importance of nonhuman primate research to society at large. The complexity of the brain and the enormity of the goal of trying to understand it are indeed daunting to contemplate. So, to some degree, it is not surprising that the general public is skeptical about whether nonhuman primate research is necessary. But a mistaken few with a very effective propaganda machine are misleading the public. Activist groups are outspoken in their attempts to sway public opinion, painting a distressingly inaccurate view of both the realities of animal research and the potential for alternative research approaches. Only the scientific community can correct this misguided view, and it's time to engage with and educate the public more effectively. There is no question that the public wants better treatments for brain diseases. To achieve our collective goal of understanding the brain - and how to fix it when things go awry-it is essential that neural functions are explored in species who share some of our most intriguing abilities.

We are not trivializing the ethics of animal use in research. In fact, this is an issue of great concern to neuroscientists. It has long been standard practice to minimize the use of nonhuman primates, reserving these animals solely for studying questions that cannot be assessed effectively in other systems. And the oversight for such experiments is rigorous, with clear guidelines for the treatment of animals aimed at minimizing discomfort. Unfortunately, in the skewed picture of animal research often presented to the public, the strictness of these guidelines and the community's overwhelming compliance are not evident. When these guidelines are breached, repercussions should be decisive. But in the

Published online 18 May 2015; doi:10.1038/nn.4039 vast majority of cases, scientists treat their animals with the utmost care. Educating the public about the protections in place for laboratory animals and the research community's robust support of these guidelines will help counteract the distorted view presented by animal rights activists. But individual researchers cannot endure this alone without support.

Although the threat posed by radical activists is not new, scientific institutions and organizations often lack an effective strategy for dealing with such problems when they arise, and their responses to these threats have been slow or absent. Research universities and institutions must rally around researchers who work with nonhuman primates, providing them with the support essential to continuing their research programs safely and successfully. Direct, proactive plans are needed to respond to the threats posed by radical activists as they develop and before they escalate into violence or investigators' abandonment of research. Research institutions have lofty goals and valuable assets. They should protect these assets and more actively defend the researchers who help them achieve their visions.

While scientists are left to suffer the consequences of such extreme actions, activists have been allowed to infringe on their basic human and societal rights with impunity. Tragically, the activists' illegal actions often go unpunished. Given their use of violence and intimidation to achieve political aims, these activists should be rightly viewed as terrorists. Just as we do not tolerate terrorism for other political aims, we must not tolerate it here. Governing bodies need to go beyond paying lip service to the importance of scientific research by creating and enforcing regulations to protect scientists on the front line of scientific investigation. Hostilities toward law-abiding scientists are unconscionable and must not be permitted.

This is not the first time that animal rights activists have used extreme tactics to intimidate scientists. When will it be the last? If more researchers abandon nonhuman primate research as a result of fears over their safety and that of their families and colleagues, we will lose ground in our fight to understand the brain and treat its diseases. While this situation unfolds as we go to press, a particularly encouraging turn of events has been the Motion for Solidarity spearheaded by Peter Thier (http://www.cin. uni-tuebingen.de/sign-open-letter.php). As of 8 May, over 3,000 supporters had signed the motion in just a few days. This swift response from the research community is heartening, but we need to transform this support into action. We should educate the public on the value and importance of animal research. We should hold our scientific institutions accountable for protecting the researchers that help them thrive. And we should lobby our governments to provide appropriate protections for those whose life's work is aimed ultimately at improving the lives of others. 